\title{
Investor's Perception towards Service Quality of DEMAT Account in Nepal
}

\author{
Shanker Dhodary \\ Shreeya Joshi
}

\begin{abstract}
The main purpose of the study is to analyze the investors' perception towards service quality of DEMAT account in Nepalese capital market. The study has used descriptive research design to measure the perception towards service quality. This study is based on primary data by administered questionnaire to the investors. Service quality and customer satisfaction are interrelated. Higher the service quality, higher will be the customer satisfaction. The research findings, shows that investor's perception towards service quality of DEMAT account meet Nepalese investor's expectations and they are satisfied with the different features of DEMAT. Further, this study also shows that the most important predictor of investor satisfaction in this study is assurance dimension.
\end{abstract}

Key words: DEMAT, Assurance, Empathy, Tangibles, Responsiveness

\section{Introduction}

Service quality and investor's satisfaction are relatively important concepts that the depository participants must understand to be able to survive and remain competitive and grow in the market. Dematerialization is the foundation of concurrent changes in the capital market in Nepal. The capital market provides a means for issuers to raise capital from the investors. Capital market is a prime medium for mobilizing the finance out of the savings of the community and making it available to the users that is to the industry, trade, commerce for meeting their fund requirements.

In Nepal, comparatively lesser number of people were interested in investing into stock market because of hefty paper works involved in trading in the market. However, our stock market has evolved over the years with the opening of more brokering offices, entry of mutual funds and credit rating agencies, increase in the number of merchant bankers, entry of production companies and increasing participation of investors in the primary market (Shrestha, 2016).

As the market grew larger, this lead to number of problems such as duplication of shares, fake shares, fake signatures, signature mismatches, difficulty in ownership transformation and as such. Physical certificate of stocks became the major reason for rising arbitration cases and investors disputes. The system of physical delivery of scrip posed many problems for the purchaser as well as the seller in the form of delayed settlements, long settlements process, high level of failed trade, high cost of transaction, bad deliveries and as such (KC, 2017). Thus, to eliminate paper work and facilitate scrip less trading and electronic book entry of the trading of securities, it became necessary to replace the conventional system of transfer and settlement with the new and modern system of depositories. Many research work has been carried in different service sectors such as telecommunications, education, health care and others. However limited empirical study has been conducted using this model to access service quality in DEMAT services.

The major objectives of the study is to analyze the investors' perception towards service quality of 
DMAT account in Nepal. However, the specific objectives of the study are listed as below:

\section{Hypotheses of the Study}

H1: Reliability has significant impact on investor's satisfaction.

H2: Responsiveness has significant impact on investor's satisfaction.

H3: Assurance has significant impact on investor's satisfaction.

H4: Empathy has significant impact on investor's satisfaction.

H5: Tangibles has significant impact on investor's satisfaction.

\section{Literature Review}

Singh \& Goyal (2011) conducted research on "Analysis of Factors Affecting Decision making of the Investors in Depository System", holds the view that most of the investors think that shorter settlement period, safety of securities with the depositories, attitude of the staff available with the DPs, timely services provided by the DPs to the investors, reduction in transaction costs, repatriation of sales proceeds of shares and debentures are some of the factors which affects the decision making of the investors in depository system. The education of the investors plays an important role in decision making where the difference in opinions of the investors are found significant in most of the cases followed by other factors such as occupation, age etc.

Singh (2012) observed the customers go for DEMAT account as it is required by the company, some go for safety mode and some to avail future opportunities. The main purpose of opening DEMAT Account is for immediate transfer of securities and elimination of risk associated with physical certificate such as bad delivery and as such. It also reduces paper work involved in transfer of securities.

Patil (2012) conducted a research entitled "A study of Respondent Satisfaction towards Depository Participants at Karvy" to know the satisfaction of customers from DP's services. He found that most of his respondents were satisfied with the service of DEMAT. However, some were not aware about the services of DP such as freezing and loan against share. He also found that investors look for quality service and safety.

Garg (2016) concluded that Dematerialization has enabled the Indian capital market to grow exponentially as measured in terms of amount raised from the market, number of stock exchanges and intermediaries, the number of listed stocks, market capitalization, trading volumes, turnover on stock exchanges and investor's population. Benefit of depository system is very significant in Indian economy. Introduction of depositories has improved the market efficiency.

Melbha (2017) analyzed importance of DEMAT account and trading account to evaluate market potential to opening DEMAT and trading account. The hypothesis is tested between opening DEMAT and trading account and the income from the investment. Finally, he concluded that the investors have many benefits like reduced trade cost, faster settlement, better portfolio management etc.

\section{Research Method}

Current research collected the perception of the investors having DEMAT account through a structured questionnaire, adopted from (Felix, 2017), aiming to examine the investor's perception towards service quality of DEMAT account in Nepal.

\section{Research Design}

Descriptive design has been used in preliminary and exploratory studies to gather information, summarize, present and interpret for the purpose of classification. Exploratory design help to examine the relationship between different service quality variables of DMAT account with that to customers' satisfaction towards service quality of DMAT account and how these dimension affect satisfaction. 


\section{Population and Sample}

The population of the study were all those people having DMAT account in Nepal. Since the population is scattered throughout Nepal and there is major concentration of large number of investors in Nepal, the investors residing in Kathmandu were only taken as sample for the research. The research has been done using convenience sampling technique. A sample of 336 DMAT account holders in urban and semi urban areas are taken for the study to know the awareness, opinions, feelings and perceptions on Nepali Depository System.

\section{Data Presentation and Analysis}

Reliability

This section express the descriptive analysis of independent variable Reliability.

Table 1

Descriptive Analysis of Reliability

\begin{tabular}{lccccc}
\hline Statements & $\mathrm{N}$ & Min & Max & Mean & S.D \\
\hline They provide the service as promised & 336 & 1 & 5 & 3.59 & 0.920 \\
They show sincere interest in solving customer's problem & 336 & 1 & 5 & 3.83 & 0.822 \\
They perform the service right the first time & 336 & 1 & 5 & 3.79 & 0.833 \\
The service is not delayed & 336 & 1 & 5 & 3.40 & 1.049 \\
\hline Records are accurately maintained & 336 & 1 & 5 & 3.85 & 0.891 \\
\hline Reliability & & & & 3.692 & 0.903 \\
\hline
\end{tabular}

Source: Opinion Survey

The table 1 exhibits the descriptive statistics of an individual item and as a whole of reliabilityservice quality dimension. This table shows the respondents' perceived rating towards reliability. Respondents were asked about reliability dimension of service quality of DEMAT account provided by their depository participants. Mean of all statements are above 3. Among four statements, the statement "Records are accurately maintained" has the highest mean 3.85 with standard deviation 0.891 , while the statement, "Service is not delayed" has the lowest mean 3.40 with the standard deviation 1.049. Mean value of all the statements ranges from 3.40 to 3.85 , which indicated that there is consistency in responses of the respondents on the specified Likert scale item. The average mean of all statements of Reliability is 3.692 with standard deviation of 0.903 . It indicates that the average score is more than three which means reliability is perceived good and satisfactory.

\section{Responsiveness}

This section express the descriptive analysis of independent variable responsiveness.

Table 2

Descriptive Analysis of Responsiveness

\begin{tabular}{lccccc}
\hline Statements & $\mathrm{N}$ & Min & Max & Mean & S.D \\
\hline Information are made easily available to the customers & 336 & 1 & 5 & 4.00 & 0.669 \\
Prompt services are given to the customers & 336 & 1 & 5 & 3.93 & 0.823 \\
The employees are always willing to help customers & 336 & 1 & 5 & 3.73 & 0.819 \\
Employees are never too busy to respond customer's requests & 336 & 1 & 5 & 3.87 & 0.852 \\
\hline Responsiveness & & & & 3.883 & 0.791 \\
\hline
\end{tabular}

Source: Opinion Survey 
The table 2 exhibits the descriptive statistics of an individual item and as a whole of responsivenessservice quality dimension. This table shows the respondents' perceived rating towards responsiveness. Respondents were asked about responsiveness dimension of service quality of DEMAT account provided by their depository participants. Mean of all statements are above 3. Among five statements, the statement "Information are made easily available to the customers" has the highest mean 4.00 with standard deviation 0.669 , while the statement, "The employees are always willing to help customers" has the lowest mean 3.73 with the standard deviation 0.819 . Mean value of all the statements ranges from 3.73 to 4.00 , which indicated that there is consistency in responses of the respondents on the specified Likert scale item. The average mean of all statements of Reliability is 3.883 with standard deviation of 0.791 . It indicates that the average score is more than three which means responsiveness is perceived good and satisfactory.

\section{Assurance}

This section express the descriptive analysis of independent variable Assurance.

Table 3

Descriptive Analysis of Assurance

\begin{tabular}{lccccc}
\hline Statements & $\mathrm{N}$ & Min & Max & Mean & S.D \\
\hline The behavior of service provider instill confidence in customers & 336 & 1 & 5 & 3.85 & 0.791 \\
The customers feel safe in their transactions with the depository & 336 & 1 & 5 & 3.63 & 0.785 \\
Employees are polite to the customers & 336 & 1 & 5 & 3.88 & 0.743 \\
Employees have knowledge to answer customer's inquires & 336 & 1 & 5 & 3.97 & 0.81 \\
\hline Assurance & & & & 3.833 & 0.782 \\
\hline
\end{tabular}

Source: Opinion Survey

The table 3 exhibits the descriptive statistics of an individual item and as a whole of Assurance- service quality dimension. This table shows the respondents' perceived rating towards Assurance. Respondents were asked about responsiveness dimension of service quality of DEMAT account provided by their depository participants. Mean of all statements are above 3. Among four statements, the statement "Employees have knowledge to answer customer's inquires" has the highest mean 3.97 with standard deviation 0.81 , while the statement, "The customers feel safe in their transactions with the depository" has the lowest mean 3.63 with the standard deviation 0.785 . Mean value of all the statements ranges from 3.63 to 3.97, which indicated that there is consistency in responses of the respondents on the specified Likert scale item. The average mean of all statements of Reliability is 3.883 with standard deviation of 0.782 . It indicates that the average score is more than three which means Assurance is perceived good and satisfactory.

\section{Empathy}

This section express the descriptive analysis of independent variable Empathy.

Table 4

Descriptive Analysis of Empathy

\begin{tabular}{lccccc}
\hline Statements & $\mathrm{N}$ & Min & Max & Mean & S.D \\
\hline The depository participant's employees give individualized & 336 & 1 & 5 & 3.60 & 0.858 \\
attention to the customers. & & & & & \\
The operating hours are convenient to the customers. & 336 & 1 & 5 & 3.93 & 0.629 \\
It has customer's best interest at heart. & 336 & 1 & 5 & 3.66 & 0.748 \\
The depository understand the specific needs of their customers. & 336 & 1 & 5 & 3.94 & 0.68 \\
\hline Empathy & & & & 3.783 & 0.729 \\
\hline
\end{tabular}


The table 4 exhibits the descriptive statistics of an individual item and as a whole of Empathy- service quality dimension. This table shows the respondents' perceived rating towards Empathy. Respondents were asked about Empathy dimension of service quality of DEMAT account provided by their depository participants. Mean of all statements are above 3. Among four statements, the statement "the depository understand the specific needs of their customers." has the highest mean 3.94 with standard deviation 0.68 , while the statement, "The depository participant's employees give individualized attention to the customers" has the lowest mean 3.60 with the standard deviation 0.858. Mean value of all the statements ranges from 3.60 to 3.94 , which indicated that there is consistency in responses of the respondents on the specified Likert scale item. The average mean of all statements of Reliability is 3.783 with standard deviation of 0.729. It indicates that the average score is more than three which means Empathy is perceived good and satisfactory.

\section{Tangibles}

This section express the descriptive analysis of independent variable Tangibles.

Table 5

Descriptive Analysis of Tangibles

\begin{tabular}{lccccc}
\hline Statements & $\mathrm{N}$ & Min & Max & Mean & S.D \\
\hline The physical facilities of the depository are appealing & 336 & 1 & 5 & 3.67 & 0.868 \\
Employees are well dressed and appear neat & 336 & 1 & 5 & 3.80 & 0.827 \\
The depository have updated equipment and services & 336 & 1 & 5 & 3.82 & 0.758 \\
\hline Tangibles & & & & 3.763 & 0.818 \\
\hline
\end{tabular}

Source: Opinion Survey

The table 5 exhibits the descriptive statistics of an individual item and as a whole of Tangibles- service quality dimension. This table shows the respondents' perceived rating towards Tangibles. Respondents were asked about Tangible dimension of service quality of DEMAT account provided by their depository participants. Mean of all statements are above 3. Among three statements, the statement "The depository have updated equipment and services." has the highest mean 3.82 with standard deviation 0.758 , while the statement, "The physical facilities of the depository are appealing" has the lowest mean 3.67 with the standard deviation 0.868. Mean value of all the statements ranges from 3.67 to 3.82, which indicated that there is consistency in responses of the respondents on the specified Likert scale item. The average mean of all statements of Reliability is 3.763 with standard deviation of 0.818 . It indicates that the average score is more than three which means Tangibles is perceived good and satisfactory.

\section{Investor's Satisfaction}

Table 6

Descriptive Analysis of Investor's Satisfaction

\begin{tabular}{lccccc}
\hline Statements & $\mathrm{N}$ & Min & Max & Mean & S.D \\
\hline You are satisfied with the trading mechanism settlement. & 336 & 1 & 5 & 3.88 & 0.819 \\
You feel safe in the transactions with your depository. & 336 & 1 & 5 & 3.9 & 0.748 \\
The share deposit features provided by your depository is & 336 & 1 & 5 & 3.9 & 0.686 \\
satisfactory. & & & & & \\
Price charged by your depository is affordable. & 336 & 1 & 5 & 3.95 & 0.685 \\
Periodic statement facility provided by the depository is satisfactory. & 336 & 1 & 5 & 3.77 & 0.691 \\
\hline Investor's Satisfaction & & & & 3.88 & 0.726 \\
\hline
\end{tabular}

Source: Opinion Survey 
The table 6 exhibits the descriptive statistics regarding the satisfaction of investors taken under study. There are five statements which relate investor's satisfaction on DEMAT account. This table shows the respondents' perceived rating towards satisfaction. Respondents were asked about different dimensions of service quality of DEMAT account provided by their depository participants. Mean of all statements are above 3.7. Among five statements, the statement, "Price charged by your depository is affordable." has the highest mean 3.95 with standard deviation 0.685 , while the statement, "Periodic statement facility provided by the depository is satisfactory." has the lowest mean 3.77 with the standard deviation 0.691 . Mean value of all the statements ranges from 3.77 to 3.95 , which indicated that there is consistency in responses of the respondents on the specified Likert scale item. The average mean of all statements of Reliability is 3.88 with standard deviation of 0.726 . It indicates that the average score is more than three which means investor's satisfaction level is perceived good.

\section{Ranking Demotivating Factors}

Table 7

Ranking Demotivating Factors

\begin{tabular}{lccccc}
\hline & $\mathrm{N}$ & Min & Max & Mean & Rank \\
\hline DEMAT charges are too high & 336 & 1 & 5 & 3.45 & 5 \\
Unauthorized debit/credit of shares & 336 & 1 & 5 & 3.01 & 3 \\
Delay in DEMAT of share & 336 & 1 & 5 & 2.17 & 1 \\
Non receipt of interest/bonus/dividend/rights & 336 & 1 & 5 & 2.77 & 2 \\
Wrong credit of shares & 336 & 1 & 5 & 3.44 & 4 \\
\hline
\end{tabular}

Source: Opinion Survey

The table 7 illustrates the descriptive analysis of the ranking question. The respondents were asked to rank demotivating factors that affect Investor's Perception towards Service Quality of DEMAT Account in Nepal. The range varied from 1 to 5, where 1 is most important factor, 2 is second important, 3 is third important, 4 is fourth important and 5 is least important factor. Here, delay in DEMAT of shares was the most important factor for investor's dissatisfaction with mean of 2.17 , followed by non receipt of interest/ Bonus/Dividend/Rights with mean of 2.77, followed by unauthorized debit/credit of shares with mean of 3.01. Wrong credit of shares and DEMAT charges are too high were ranked important factors of customer dissatisfaction by the respondents with mean of 3.44 and 3.45 respectively.

\section{Correlation Analysis}

Pearson's Correlation analysis has been carried out to analyze the degree and direction of relationship among the variables. The result of correlation analysis in the table indicated that the data shows a positive relation between dependent and independent variables.

Table 8

Correlation Analysis of Investor's Satisfaction and Independent Variables

\begin{tabular}{|c|c|c|c|c|c|c|}
\hline Pearson & $\begin{array}{c}\text { Investors' } \\
\text { Satisfacti-on }\end{array}$ & Reliability & Responsiveness & Assurance & Empathy & Tangibles \\
\hline Investors' & & & & & & \\
\hline Satisfaction & 1 & & & & & \\
\hline Reliability & $0.442 * *$ & 1 & & & & \\
\hline Responsiveness & $0.461 * *$ & $0.407 * *$ & 1 & & & \\
\hline
\end{tabular}


Assurance

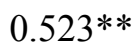

$0.359 * *$

$0.511 * *$

\section{1}

Empathy

$0.395^{* *}$

$0.355^{* *}$

$0.347 * *$

$0.388^{* *}$

$0.446 * *$

$0.539 * *$

1

Tangibles

$0.402 * * \quad 0.318^{* *}$

1

** Correlation is significant at 0.01 level (2-tailed)

Source: Opinions Survey

The table 8 reveals result of the Pearson's correlation coefficient between Investor's satisfaction and the independent variables taken under study. The highest correlation coefficient of Investor's Satisfaction can be observed as 0.523 with Assurance variable. It means an increase in Assurance can lead to increase in Investor's satisfaction and the relationship is significant at 1 percent level of significance. Hence good assurance by depository unit ensures higher satisfaction level in investors.

In conclusion, we can say that, assurance factor has the strongest positive association with investor's satisfaction $(\mathrm{r}=0.523)$, followed by Responsiveness of depository unit $(\mathrm{r}=0.461)$ and Reliability $(\mathrm{r}=$ 0.442). Tangibles $(r=0.402)$ and Empathy $(r=0.395)$ also has a positive association with investor's satisfaction toward services provided by depository units in Nepal.

\section{Multiple Regression Analysis}

Regression analysis has been carried out to know the variability and significance of the variables taken under study. The independent variables are Reliability, Responsiveness, Assurance, Empathy and Tangibles whereas dependent variable is Investors' Satisfaction. The table shows the regression analysis of the relationship between the dependent and independent variables based on 336 observations by using liner regression model:

$$
\mathrm{CS}=\square \square+\beta \square \operatorname{Rel}+\beta \square \operatorname{Res}+\beta \square \mathrm{As}+\beta \square \mathrm{Em}+\beta \square \operatorname{Tan}+\square
$$

CS represents Customer Satisfaction, Rel is Reliability, Res denotes Responsiveness, as is Assurance, Em is Empathy, Tan is Tangibles, $\square \square$ is Constant Term and $\square$ is Error term.

Table 9

Multiple Regression Analysis

\begin{tabular}{lllll}
\hline Model & $\mathrm{R}$ & R Square & Adjusted R Square & $\mathrm{F}$ \\
\hline 1 & 0.627 & 0.393 & 0.384 & 42.819 \\
\hline
\end{tabular}

Source: opinion survey

The table 9 represents $\mathrm{R}$ Square for this model, which is 0.393 . This means that $39.9 \%$ of the variation in the dependent variable Investors' Satisfaction can be explained by five independent variables (Reliability, Responsiveness, Assurance, Empathy, Tangibles). The fitness of the model is stated significant at F- value of 42.819. The significant $\mathrm{F}-$ Statistics value provides the best fit of the model.

Table 10

Regression Coefficients

\begin{tabular}{llccccc}
\hline Model & & \multicolumn{2}{c}{ Unstandardized Coefficients } & $\begin{array}{c}\text { Standardized } \\
\text { Coefficients }\end{array}$ & $\mathrm{t}$ & Sig. \\
\hline \multirow{3}{*}{1} & Constant & 1.147 & Std. Error & Beta & & 0.000 \\
& Reliability & 0.166 & 0.193 & & 5.949 & 0.000 \\
& Responsiveness & 0.127 & 0.040 & 0.205 & 4.159 & 0.005 \\
& & & & 0.151 & 2.822 & 0.000
\end{tabular}


Silver Jubilee Issue - 2019

\begin{tabular}{llllll} 
Assurance & 0.230 & 0.048 & 0.269 & 4.761 & 0.000 \\
Empathy & 0.129 & 0.043 & 0.144 & 2.965 & 0.003 \\
Tangibles & 0.069 & 0.041 & 0.090 & 1.710 & 0.088 \\
\hline
\end{tabular}

Source: opinion survey

An equation can be formed by referring to the table to determine the statistical significance of each independent variable on the dependent variable. The result of the regression analysis show that reliability, responsiveness, assurance and empathy has $\mathrm{P}$ value less than alpha at $5 \%$ significance level. Thus, it can be concluded that the aforementioned variables have a positive and significant relation with the investor's satisf0action. However tangible factor has $\mathrm{P}$ value alpha at more than $5 \%$ significance level, so it is considered insignificant.

By referring to the table, an equation can be formed to determine the statistical significance of each independent variable on dependent variable.

\section{Equation}

Investors' Satisfaction $=1.147+0.166 *$ Reliability $+0.127 *$ Responsiveness $+0.230^{*}$ Assurance + $0.127 *$ Empathy

According to the liner equation of this study, Assurance has the highest impact on Investor's Satisfaction. Holding other independent variables constant, every one unit increase in Assurance will increase 0.230 units of Investor's Satisfaction level, followed by Reliability $(\beta=0.166)$, Empathy $(\beta=0.129)$ and Responsiveness $(\beta=0.127)$.

\section{Major Findings}

Service quality and customer satisfaction are interrelated. Higher the service quality, higher be the customer satisfaction. It shows that investor's perception towards service quality of DEMAT account meet Nepalese investor's expectations and they are satisfied with the different features of DEMAT. This study also shows that the most important predictor of investor satisfaction in this study is assurance dimension. Furthermore, following conclusions has been generated from the study findings in relation to the study objectives set previously:

It indicates that investors perceive that service of DEMAT account has quality and meet their expectations. Hence from all the findings, we can conclude that investor's perception towards service quality of DEMAT account meet their expectations, they are satisfied with the different features of DEMAT. It has shown that the delay in DEMAT of shares was the most important factor for investor's dissatisfaction. It can be conclude that investor's perception towards service quality of DEMAT account meet their expectations, they are satisfied with the different features of DEMAT.

\section{Suggestion for Future Research}

This research is based on Nepalese depository participants in general. Further research could be made in investors' preferential attitude towards DEMAT service provider; where investors' preference towards a depository can be measured against investors' attitude towards other depository. This could help to examine whether there is a difference between the services provided by different depositories.

The samples were taken from Kathmandu city only, which could be extended throughout Kathmandu Valley, which might add new insights to the results of the current study. A larger sample size may discover a difference between gender and motivational factors for choosing the depository, this study could not validate due an insufficient sample size. Similarly, future research could be made on reasons for investors' choice of depositors. 


\section{References}

Felix, R. (2017). Service Quality and Customer Satisfaction in Selected Banks in Rwanda. Journal of Business \& Financial Affairs.

Garg, D. (2012). Depository system in India : An appraisal. International Journal of Research in Finance \& Marketing, 57-67.

Garg, Y. (2016). An Exploratory Study on Dematrialization and Depository System in India. International Research Journal of Commerce Arts and Science, 36-40.

KC, R. (2017, January 27). A Medium Corporation. Retrieved from medium.com: https://medium.com/ bizserve/how-central-depository-system-cds-works-in-nepal-ecb042f7d3c9

Melbha, D. (2017). A Market Potential of Open the Demat Account and trading Account for Trading in Stock Exchange. International Journal of Research in Business Management, 107-114.

Patil, B. (2012). A project report on customer satisfaction towards depository participants at karvy.

Saravanakumar, A., \& Ganesan, D. M. (2017). Investors' awareness on Demat account: A study in Sulur taluk, Coimbatore district. International Journal of Academic Research and Development, 301-304.

Shrestha, R. B. (2016, December). Beed. Retrieved from beed.com.np: http://www.beed.com.np/beedinsights/article.php?id=85

Singh, Jasbir (2012). Awareness of Customers Regarding to DEMAT Account. International Journal of Transformations in Business Management.

Singh, P. S., \& Goyal, S. (2011). Analysis of Factors Affecting Decision making of the Investors in Depository System. Journal of Banking, Financial Services and Insurance Research, 13-38. 
